\title{
Effect of light-curing time on light-cure/post-cure volumetric polymerization shrinkage and regional ultimate tensile strength at different depths of bulk-fill resin composites
}

\author{
Kurumi IDE ${ }^{1}$, Masatoshi NAKAJIMA ${ }^{1}$, Juri HAYASHI ${ }^{1}$, Keiichi HOSAKA ${ }^{1}$, Masaomi IKEDA², Yasushi SHIMADA ${ }^{3}$, \\ Richard M. FOXTON ${ }^{4}$, Yasunori SUMI ${ }^{5}$ and Junji TAGAMI ${ }^{1,6}$ \\ ${ }^{1}$ Department of Cariology and Operative Dentistry, Graduate School of Medical and Dental Sciences, Tokyo Medical and Dental University (TMDU), \\ 1-5-45, Yushima, Bunkyo-ku, Tokyo 113-8549, Japan \\ ${ }^{2}$ Department of Oral Prosthetic Engineering, Graduate School, Faculty of Dentistry, Tokyo Medical and Dental University (TMDU), 1-5-45, Yushima, \\ Bunkyo-ku, Tokyo 113-8549, Japan \\ ${ }^{3}$ Department of Operative Dentistry, Graduate School of Medicine, Dentistry and Pharmaceutical Sciences, Okayama University, 2-5-1, Shikata-cho, \\ Kita-ku, Okayama 700-8525, Japan \\ ${ }^{4}$ Division of Conservative Dentistry, King's College London Dental Institute at Guy's, King's and St Thomas' Hospitals, King's College London, Floor \\ 25, London Bridge, London, SE1-9RT, UK \\ ${ }^{5}$ National Center for Geriatrics oand Gerontology, Department of Advanced Dental Research, Center of Advanced Medicine for Dental and Oral \\ Disease, 7-430, Morioka-cho, Obu-shi, Aichi 474-8511, Japan \\ ${ }^{6}$ Global Center of Excellence Program; International Research Center for Molecular Science in Tooth and Bone Diseases, Tokyo Medical and Dental \\ University, 1-5-45 Yushima, Bunkyo-ku, Tokyo 113-8549, Japan \\ Corresponding author, Masatoshi NAKAJIMA; E-mail: nakajima.ope@tmd.ac.jp
}

The aim of this study was to investigate volumetric polymerization shrinkage (VS), using swept-source optical coherence tomography (SS-OCT), of bulk-fill composites with different light-curing strategies; immediately after light-irradiation and after $24 \mathrm{~h}$, and to evaluate their regional ultimate tensile strength (UTS) at different curing depths. The immediate VS after photo-polymerization decreased when the curing light-curing time was reduced from 20 to 10 to $5 \mathrm{~s}$. On the other hand, their VS values after $24 \mathrm{~h}$ significantly increased due to the post-cure polymerization, resulting in similar VS values at all the light-curing times. Five seconds light-curing decreased the regional UTS of resin composites after the $24 \mathrm{~h}$ period compared with the 10 and $20 \mathrm{~s}$ light-curing regimes; therefore, the remarkable progress of post-cure polymerization after light-curing for a short time would not lead to an improvement in the mechanical properties of resin composites. The influence of the light-curing time on the curing depth was dependent upon the bulk-fill composite material.

Keywords: Bulk fill, Volumetric shrinkage, Depth of cure, Optical coherence tomography, Ultimate tensile strength

\section{INTRODUCTION}

Light-cured resin composites have been widely used as a direct filling material for esthetically restoring loss of tooth structure. Their physical properties, such as compressive and tensile strength, elastic modulus, polymerization shrinkage, contraction stress and degree of conversion, play significant roles in the clinical success of resin composite restorations, and light irradiation protocols affect them ${ }^{1-3)}$. When filling and light-curing conventional resin composites in deep cavities, several increments should be placed because their appropriate curing depths are up to $2 \mathrm{~mm}$ depth$^{4}$. Additionally, this incremental filling technique can reduce contraction stress of resin composite to cavity walls by minimizing the volume of resin composite cured at one time $^{5)}$. However, incremental placement is a time-consuming procedure.

Recently, a new category of resin composites "bulkfill composite" has been introduced to simplify the filling procedure. Generally, increasing the volume of resin composite, which is placed in a cavity, would cause greater contraction stress at the cavity walls, depending upon the c-factor. The contraction stress of resin composite can lead to cusp displacement and gap formation at the interface between the tooth and restoration. Gaps and lack of integrity at the tooth-composite interface would compromise the clinical prognosis of the restoration because they could cause bacterial micro-leakage, secondary caries and hypersensitivity ${ }^{6)}$. However, manufacturers claim that bulk-fill composites can be bulk-filled and light-cured in cavities up to $4 \mathrm{~mm}$ in depth with low volumetric polymerization shrinkage (VS), resulting in low contraction stress.

Many studies on bulk-fill composites have been published on bond strength ${ }^{7)}$, gap formation ${ }^{8)}$, cuspal deflection $^{9,10)}$, mechanical properties ${ }^{11-13)}$, degree of conversion $^{11-14)}$, depth of cure ${ }^{15,16)}$, polymerization shrinkage $^{13,15,16)}$, contraction stress $^{11,13,16)}$. The polymerization shrinkage of resin composites has been investigated by linear or volumetric measurement using various methods; dilatometer ${ }^{17,18)}$, gas pycnometer ${ }^{19)}$, buoyancy method ${ }^{13)}$, modified linometer ${ }^{20,21)}$, bonded-disk method $^{22)}$, the use of a strain gauge ${ }^{22)}$, and digital videoimaging method ${ }^{23)}$. Their studies have demonstrated that the polymerization shrinkage of resin composites occurs rapidly after the start of light-irradiation and continues even after the end of the light-irradiation. As long as 
there are activated free radicals and reactants present after the primary light-cure phase, the polymerization process will continue. Some studies have reported that post-cure polymerization continued up to or beyond $24 \mathrm{~h}$ after light-irradiation ${ }^{14,24)}$. Additionally, it has been reported that composite specimens with a low level of polymerization after the primary light-curing phase generated greater post-cure polymerization ${ }^{14,24)}$. Recently, non-contact 2D and 3D imaging methods such as micro-computed tomography ${ }^{10,25)}$ and optical coherence tomography ${ }^{26,27)}$ have been employed to investigate the sealing performance of resin composite in cavities. Swept-source optical coherence tomography (SS-OCT) can obtain 2D and 3D cross-sectional images of teeth and periodontal tissues in a non-invasive and nondestructive way, and analyze the behavior of restorative materials inside the cavity in real time ${ }^{26,28)}$. Therefore, this method would enable the VS of resin composite in cavities to be investigated during light-irradiation, and $24 \mathrm{~h}$ later or more.

For bulk-fill composites, investigation of the curing depth is important because it usually refers to the filling thickness of a resin composite that is adequately cured. Raman micro spectroscopy can directly evaluate the curing depth of resin composites by measuring the degree of conversion at the different depths ${ }^{11,24)}$. On the other hand, the microhardness test can indirectly evaluate the curing depth because microhardness values at different depths within a resin composite specimen reflect the degree of conversion ${ }^{29}$. However, their values cannot be used to compare the degree of conversion between different resin materials, because these are strongly influenced by filler type, size and/or loading. Measurement of regional ultimate tensile strength (UTS) of resin composites using the microtensile test is useful for evaluating the curing depth of resin composite and comparing the mechanical properties of different resin composite material ${ }^{30)}$.

Most of the published studies have reported polymerization shrinkage data a short time after lightirradiation. The polymerization shrinkage of resin composites occurring during post-cure polymerization was reported to be quite appreciable ${ }^{17,18,31)}$. However, it is unclear whether post-cure polymerization would affect the mechanical properties of resin composites. The aim of this study was therefore to investigate the VS of bulk-fill and conventional composites using SSOCT immediately after light-curing and after $24 \mathrm{~h}$, and to investigate their regional UTSs at different depths.

\section{MATERIALS AND METHODS}

\section{Study materials}

Three bulk-fill composites; Filtek Bulk Fill Flowable (FBF), Beautiful Bulk Flowable (BBF), Estelite Bulk Fill Flow (EBF) and one conventional flowable composite, Estelite Flow Quick (EFQ), were used in this study (Table 1).

\section{Volumetric shrinkage measurement}

1) Specimen preparation

A rubber mold (thickness of $5 \mathrm{~mm}$ ) with a standardized cylinder-shaped hole (diameter of $3 \mathrm{~mm}$ ) was prepared, and a $1 \mathrm{~mm}$ thick glass plate was placed at the bottom

Table 1 Resin composite materials used in this study

\begin{tabular}{|c|c|c|c|c|}
\hline $\begin{array}{l}\text { Material } \\
\text { Type }\end{array}$ & Shade & Composition & $\begin{array}{l}\text { Manufactures' } \\
\text { curing time (s) } \\
\text { Curing depth } \\
\quad(\mathrm{mm})\end{array}$ & Manufacturer \\
\hline $\begin{array}{l}\text { Estelite Bulk } \\
\text { Fill Flow } \\
{[\mathrm{EBF}]}\end{array}$ & Universal & $\begin{array}{l}\text { Filler contents/ } 56 \text { vol\% } 70.0 \text { wt } \% \\
\text { New organic inorganic hybrid filler, surpra nano } \\
\text { spheroidal filler }\left(\mathrm{SiO}_{2} \text {-ZrOs), Bis-GMA, TEGDMA, }\right. \\
\text { BisMPEPP, CQ, Radical-Amplified } \\
\text { Photopolymerization initiator }\end{array}$ & $\begin{array}{r}10 \\
4\end{array}$ & $\begin{array}{l}\text { Tokuyama } \\
\text { Dental }\end{array}$ \\
\hline $\begin{array}{l}\text { Filtek Bulk } \\
\text { Fill Flowable } \\
{[\text { FBF] }}\end{array}$ & Universal & $\begin{array}{l}\text { Filler contents/ } 42.5 \text { vol\% } 64 \mathrm{wt} \% \\
\text { ytterbium trifluoride filler with range of particles sizes } \\
\text { from } 0.1 \text { to } 5.0 \text { microns, zirconia/silica with a particle } \\
\text { size range of } 0.001 \text { to } 3.5 \mu \mathrm{m} \text {, Bis-GMA, UDMA, } \\
\text { Bis-EMA, Procrylat resins }\end{array}$ & $\begin{array}{r}20 \\
4\end{array}$ & 3M ESPE \\
\hline $\begin{array}{l}\text { Beautifill Bulk } \\
\text { Flowable } \\
{[\text { BBF] }}\end{array}$ & Universal & $\begin{array}{l}\text { Filler contents/ } 51.0 \text { vol } \% 73.0 \text { wt } \% \\
\text { Fluoro-alumino-silicate glass, Bis-GMA, UDMA, } \\
\text { Bis-MPEPP, TEGDMA, Reaction initiator, Others }\end{array}$ & $\begin{array}{r}20 \\
4\end{array}$ & $\begin{array}{l}\text { SHOFU } \\
\text { INC }\end{array}$ \\
\hline $\begin{array}{l}\text { Estelite } \\
\text { Flow Quick } \\
\text { [EFQ] }\end{array}$ & CE (Inc) & $\begin{array}{l}\text { Filler contents/ } 53 \text { vlo\% } 71.0 \mathrm{wt} \% \\
\text { Silicazirconia filler, silica-titania filler, Bis-MPEPP, } \\
\text { TEGDMA, UDMA, CQ, Radical-Amplified } \\
\text { Photopolymerization initiator }\end{array}$ & $\begin{array}{r}20 \\
2\end{array}$ & $\begin{array}{l}\text { Tokuyama } \\
\text { Dental }\end{array}$ \\
\hline
\end{tabular}


of the mold. Before placement, the surface of the glass plate was treated with a silane coupling bonding agent; a mixture of Clearfil Photobond (Kuraray Noritake Dental, Tokyo, Japan) and Clearfil Porcelain Bond activator (Kuraray Noritake Dental) followed by lightcuring for $10 \mathrm{~s}$. The tested composites were placed into the mold in bulk. After placement, the restoration in the hole was checked using SS-OCT (OCT-2000, Santec, Komaki, Japan) for any over and under filling of the resin materials and/or any internal voids. Then the resin composites were light-cured using a halogen lightcuring unit (Optilux501, Kerr, Middleton, WI, USA) with the power density of $600 \mathrm{~mW} / \mathrm{cm}^{2}$ for 5,10 , and 20 $\mathrm{s}$ by placing the tip of the light source on the glass plate at the bottom of resin composite.

2) SS-OCT optical observation of surface displacements The swept-source OCT system was used to monitor the free surface displacements at the upper surface of the resin composites after light-curing. In this system, the center wavelength is $1,330 \mathrm{~nm}$ (bandwidth $110 \mathrm{~nm}$ ) with a $30-\mathrm{kHz}$ sweep rate. The optical resolution is 20 $\mu \mathrm{m}$ transversally and $12 \mu \mathrm{m}$ axially in air. The laser beam scans the object in $\mathrm{X}$ and $\mathrm{Z}$ dimensions. Collected backscattered light from the sample is returned to the system, digitized in time scale, and analyzed in the Fourier domain to form a depth-resolving scan (A-scan) at each point. A serial set of A-scans along a certain section creates a row data file of back-scattered signal intensity (B-scan) and a 2-dimensional cross-sectional (2D) image ${ }^{26)}$.

The handheld scanning probe connected to the SSOCT was set at a fixed distance $(5 \mathrm{~cm})$ over the specimen with the scanning beam oriented $90^{\circ}$ with respect to the top surface of the mold. SS-OCT 2D scans were obtained immediately after light-curing. Six cross-sectional images were acquired at $0^{\circ}, 30^{\circ}, 60^{\circ}, 90^{\circ}, 120^{\circ}, 150^{\circ}$ planes across the specimen by rotating the SS-OCT beam. The filled specimens were stored in a dry and dark condition at $22^{\circ} \mathrm{C}$ for $24 \mathrm{~h}$ and then scanned by SS-OCT in the same manner. To replicate the imaging location each time, the specimen was marked with a pen and placed in the same orientation as previous scans.

3) Measuring volumetric shrinkage on the SS-OCT image

On the SS-OCT images imported to image analysis software (ImageJ v1.51, Wayne Rasband, NIH, Bethesda, MD, USA), seven points (a, b, c, d, e, f, g) were set with the interval of $0.5 \mathrm{~mm}$ at a line referred from the upper surface of the mold (Fig. 1). The distance (A, B, C, D, $\mathrm{E}, \mathrm{F}, \mathrm{G})$ in the vertical direction to the surface of the light-cured resin composite at each point $(\mathrm{a}, \mathrm{b}, \mathrm{c}, \mathrm{d}, \mathrm{e}$, f, g) was measured on six SS-OCT images $\left(0^{\circ}, 30^{\circ}, 60^{\circ}\right.$, $\left.90^{\circ}, 120^{\circ}, 150^{\circ}\right)$. From the data of these distances, the VS of the resin composite at each measurement period (immediately after curing, after $24 \mathrm{~h}$ ) was calculated from the following equation.

$$
\mathrm{v} 1=0.5 \times 0.5 \times \pi \times\left(\frac{\frac{\mathrm{C}+\mathrm{D}}{2}+\frac{\mathrm{D}+\mathrm{E}}{2}}{2}\right): \text { Amount of volumetric }
$$

shrinkage at central area on each SS-OCT image.

$\mathrm{v} 2=(1.0 \times 1.0-0.5 \times 0.5) \times \pi \times\left(\frac{\frac{\mathrm{B}+\mathrm{C}}{2}+\frac{\mathrm{E}+\mathrm{F}}{2}}{2}\right):$ Amount of volumetric shrinkage at middle area on each SSOCT image.

$\mathrm{v} 3=(1.5 \times 1.5-1.0 \times 1.0) \times \pi \times\left(\frac{\frac{\mathrm{A}+\mathrm{B}}{2}+\frac{\mathrm{F}+\mathrm{G}}{2}}{2}\right):$ Amount of volumetric shrinkage at peripheral area on each SSOCT image.

$\mathrm{v}=\mathrm{v} 1+\mathrm{v} 2+\mathrm{v} 3$ : Total amount of volumetric shrinkage on each SS-OCT image.

VS (Volumetric shrinkage of the one sample)= $\frac{\mathrm{v}\left(0^{\circ}\right)+\mathrm{v}\left(30^{\circ}\right)+\mathrm{v}\left(60^{\circ}\right)+\mathrm{v}\left(90^{\circ}\right)+\mathrm{v}\left(120^{\circ}\right)+\mathrm{v}\left(150^{\circ}\right)}{6}$ : Volumetric

shrinkages $\left(\mathrm{v}\left(0^{\circ}\right), \mathrm{v}\left(30^{\circ}\right), \mathrm{v}\left(60^{\circ}\right), \mathrm{v}\left(90^{\circ}\right), \mathrm{v}\left(120^{\circ}\right)\right.$, $\left.\mathrm{v}\left(150^{\circ}\right)\right)$ on the $0^{\circ}, 30^{\circ}, 60^{\circ}, 90^{\circ}, 120^{\circ}$ and $150^{\circ} \mathrm{SS}$ OCT images.

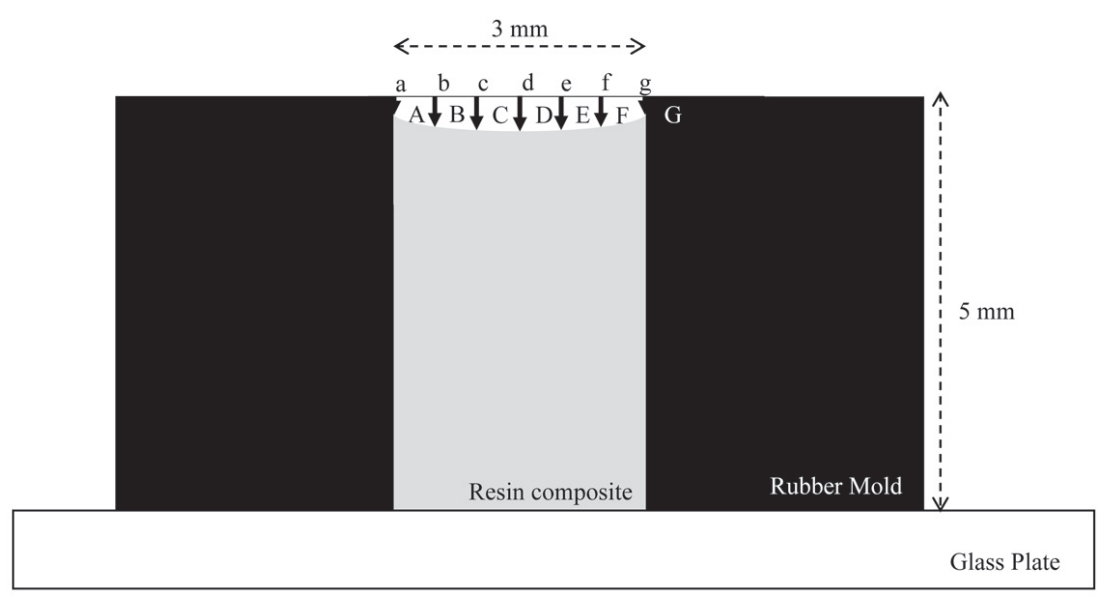

Fig. 1 Measurement point and distance for obtaining VS. 
Ultimate microtensile strength test

1) Specimen preparation

A cavity (depth of $5 \mathrm{~mm}$ and diameter of $8 \mathrm{~mm}$ ) was prepared in a ABS resin block $\left(1 \times 1 \times 1 \mathrm{~cm}^{3}\right)$. An impression of the cavity was taken using putty and regular type hydrophilic vinyl polysiloxane impression material (Exahiflex, GC, Tokyo, Japan). Forty replicas of the cavity model were fabricated by filling the impression mold with dual-cure resin composite (ESTE CORE, Tokuyama Dental, Tokyo, Japan), and light-cured with the halogen light-curing unit for $60 \mathrm{~s}$, and finally cured with a laboratory light-curing unit ( $\alpha$-light II, J. Morita, Tokyo, Japan) for $10 \mathrm{~min}$ to ensure complete polymerization of the resin composite. The models were then stored for one week in water before their use.

The internal surface of the cavity was superficially abraded using an abrasive point (Shofu, Kyoto, Japan) mounted in a low-speed handpiece under water spray, and prepared without any bonding procedure. All the external surfaces, except the cavity opening side of the model, were covered with black paper tape to prevent light passing through the composite walls during lightcuring. All the cavities were then bulk filled with one of the resin composites without surface treatment. The upper surface of each specimen was covered with a plastic strip and pressed with a glass slide to squeeze out any excess resin composite. The specimens were then light-cured with a halogen light-curing unit with power density of $600 \mathrm{~mW} / \mathrm{cm}^{2}$ for 5,10 , and $20 \mathrm{~s}$ by placing the tip of the light source at the top of the cavity. The specimens were then stored in $37^{\circ} \mathrm{C}$ water for $24 \mathrm{~h}$.

\section{2) Regional UTS measurement}

After $24 \mathrm{~h}$ storage, each specimen was attached to the arm of a low speed diamond saw (Isomet, Buehler,
Lake Bluff, IL, USA) and sectioned in the middle region parallel to the axial cavity wall twice, to obtain $2 \mathrm{~mm}$ wide slabs. One slab was then fixed at its base and serially sliced five times starting from the top surface of filled resin composite to harvest 5, $0.65 \mathrm{~mm}$-thick beams representing five depth levels of the restoration. The beams were then trimmed to an hour-glass shape with a width of $0.65 \mathrm{~mm}$ at their narrowest region. The crosssectional area of each beam was measured using a digital caliper (Mitutoyo CD15, Mitutoyo, Kawasaki, Japan). The ends of the beams were glued to a testing device in a table-top testing machine (EZ-SX, Shimadzu, Kyoto, Japan) using cyanoacrylate glue (Model Repair II Blue, Dentisply-Sankin, Tokyo, Japan) and subjected to a tensile force at a crosshead speed of $1 \mathrm{~mm} / \mathrm{min}$ (Fig. 2). UTS was calculated by dividing the fracture load by the surface area.

\section{Statistical analysis}

The VS and UTS data ware analyzed by three-way ANOVA and $t$-test with Bonferroni correction. All statistical tests were performed at a 95\% level of confidence.

\section{RESULTS}

\section{Volumetric shrinkage}

The means and standard deviations of the $\mathrm{VS}$ of resin composites are shown in Table 2. Three-way ANOVA revealed that VS were significantly different according to the resin composite materials, light-curing time, and measurement period $(p<0.0001)$. There was a significant interaction in the VS data among resin composite materials, light-curing time and measurement time $(p=0.043)$. For VS measured immediately after light-
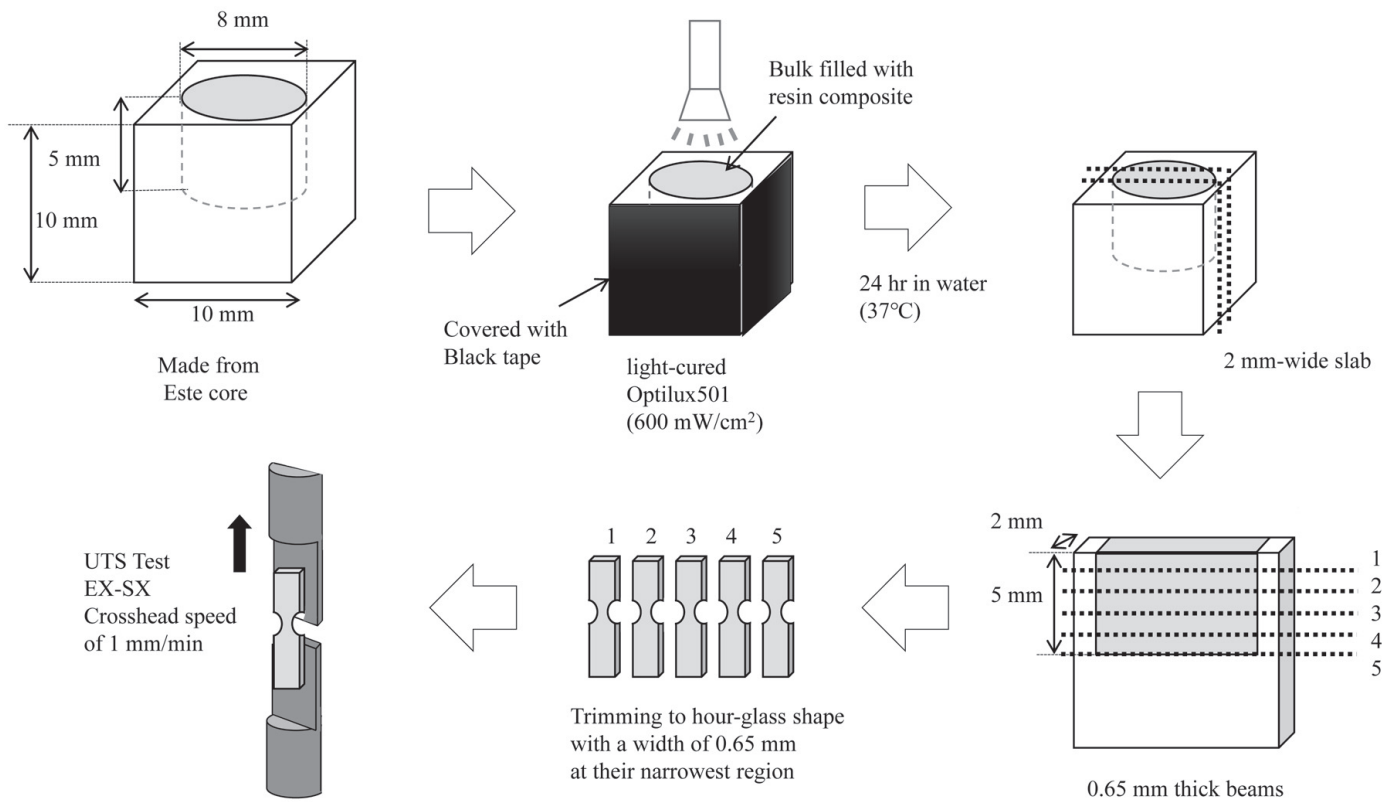

Fig. 2 Schematic view of the method used in this study. 
Table 2 The means and standard deviations of volumetric shrinkage (\%)

\begin{tabular}{|c|c|c|c|c|}
\hline \multicolumn{5}{|l|}{ Immediately after curing } \\
\hline Light-curing time (s) & $\mathrm{EBF}$ & $\mathrm{FBF}$ & $\mathrm{BBF}$ & EFQ \\
\hline 20 & $1.54(0.16)^{\mathrm{aAB}}$ & $1.78(0.15)^{\mathrm{aA}}$ & $1.09(0.19)^{\mathrm{aC}}$ & $1.37(0.24)^{\mathrm{aB}}$ \\
\hline 10 & $1.46(0.06)^{\mathrm{aA}}$ & $1.43(0.14)^{\mathrm{bA}}$ & $0.77(0.14)^{\mathrm{bC}}$ & $1.07(0.17)^{\mathrm{bB}}$ \\
\hline 5 & $1.13(0.09)^{\mathrm{bA}}$ & $1.14(0.22)^{\mathrm{cA}}$ & $0.57(0.08)^{\mathrm{bB}}$ & $0.80(0.13)^{\mathrm{cB}}$ \\
\hline \multicolumn{5}{|l|}{ After $24 \mathrm{~h}$} \\
\hline Light-curing time (s) & $\mathrm{EBF}$ & $\mathrm{FBF}$ & $\mathrm{BBF}$ & $\mathrm{EFQ}$ \\
\hline 20 & $1.96(0.22)^{\mathrm{aB}}$ & $2.10(0.16)^{\mathrm{aAB}}$ & $1.62(0.21)^{\mathrm{aB}}$ & $2.46(0.32)^{\mathrm{bA}}$ \\
\hline 10 & $1.97(0.10)^{\mathrm{aAB}}$ & $1.78(0.16)^{\mathrm{aBC}}$ & $1.43(0.33)^{\mathrm{aC}}$ & $2.35(0.12)^{\mathrm{bA}}$ \\
\hline 5 & $2.28(0.33)^{\mathrm{aB}}$ & $1.74(0.23)^{\mathrm{aC}}$ & $1.43(0.33)^{\mathrm{aC}}$ & $2.84(0.30)^{\mathrm{aA}}$ \\
\hline
\end{tabular}

Means (S.D); $n=5$.

Same small letters within columns indicates no significant difference for individual material at each measurement time.

Same capital letters within rows indicates no significant difference for individual curing time at each measurement time.

Table 3 UTS of the investigated resin composites (MPa)

\begin{tabular}{|c|c|c|c|c|}
\hline \multirow{2}{*}{ Material } & \multirow{2}{*}{$\begin{array}{c}\text { Depth } \\
(\mathrm{mm})\end{array}$} & \multicolumn{3}{|c|}{ Light curing time } \\
\hline & & $20 \mathrm{~s}$ & $10 \mathrm{~s}$ & $5 \mathrm{~s}$ \\
\hline \multirow{5}{*}{$\mathrm{EBF}$} & 1 & $99.0(10.3)^{\mathrm{aA}}$ & $103.0(12.1)^{\mathrm{aA}}$ & $85.0(14.5)^{\mathrm{aB}}$ \\
\hline & 2 & $100.9(9.8)^{\mathrm{aA}}$ & $104.4(12.9)^{\mathrm{aA}}$ & $89.1(11.5)^{\mathrm{aB}}$ \\
\hline & 3 & $102.5(15.6)^{\mathrm{aA}}$ & $97.6(12.3)^{\mathrm{abA}}$ & $84.1(12.1)^{a B}$ \\
\hline & 4 & $99.6(8.7)^{\mathrm{aA}}$ & $95.4(11.9)^{\mathrm{abA}}$ & $79.8(13.8)^{\mathrm{abB}}$ \\
\hline & 5 & $82.0(11.5)^{\mathrm{bA}}$ & $84.8(16.2)^{\mathrm{bA}}$ & $65.0(14.1)^{\mathrm{bB}}$ \\
\hline \multirow{5}{*}{$\mathrm{FBF}$} & 1 & $91.1(12.4)^{\mathrm{aA}}$ & $95.3(12.1)^{\mathrm{aA}}$ & $69.4(10.6)^{\mathrm{aB}}$ \\
\hline & 2 & $96.2(13.0)^{\text {aA }}$ & $96.5(11.3)^{\mathrm{aA}}$ & $70.5(6.6)^{\mathrm{aB}}$ \\
\hline & 3 & $94.1(11.9)^{\mathrm{aA}}$ & $92.6(9.7)^{\mathrm{aA}}$ & $68.1(7.1)^{\mathrm{aB}}$ \\
\hline & 4 & $90.6(12.7)^{\mathrm{aA}}$ & $96.3(9.2)^{\mathrm{aA}}$ & $65.4(7.0)^{\mathrm{aB}}$ \\
\hline & 5 & $83.8(11.9)^{\mathrm{aA}}$ & $83.3(9.3)^{\mathrm{aA}}$ & $58.9(13.5)^{\mathrm{aB}}$ \\
\hline \multirow{5}{*}{$\mathrm{BBF}$} & 1 & $90.4(11.2)^{\mathrm{aA}}$ & $92.7(10.3)^{\mathrm{aA}}$ & $81.7(5.6)^{\mathrm{aA}}$ \\
\hline & 2 & $81.4(11.2)^{\mathrm{aA}}$ & $84.8(9.4)^{\mathrm{abA}}$ & $86.0(8.1)^{\mathrm{aA}}$ \\
\hline & 3 & $89.0(12.4)^{\mathrm{aA}}$ & $88.1(5.9)^{\mathrm{abA}}$ & $72.1(8.6)^{\mathrm{bB}}$ \\
\hline & 4 & $81.4(14.3)^{\mathrm{aA}}$ & $78.5(8.1)^{\mathrm{bcA}}$ & $63.5(5.2)^{\mathrm{bB}}$ \\
\hline & 5 & $80.8(13.1)^{\mathrm{aA}}$ & $70.9(10.8)^{\mathrm{cA}}$ & $54.9(9.0)^{\mathrm{cB}}$ \\
\hline \multirow{5}{*}{$\mathrm{EFQ}$} & 1 & $98.1(12.9)^{\mathrm{aA}}$ & $99.0(14.8)^{\mathrm{aA}}$ & $79.6(11.2)^{\mathrm{aB}}$ \\
\hline & 2 & $100.4(12.5)^{\mathrm{aA}}$ & $102.4(11.4)^{\mathrm{aA}}$ & $76.2(8.6)^{\mathrm{abB}}$ \\
\hline & 3 & $92.4(7.4)^{\mathrm{aA}}$ & $99.7(7.8)^{\mathrm{aA}}$ & $63.9(18.3)^{\mathrm{bcB}}$ \\
\hline & 4 & $86.1(14.4)^{\mathrm{abA}}$ & $83.6(6.1)^{\mathrm{bA}}$ & $49.8(7.7)^{\mathrm{cB}}$ \\
\hline & 5 & $74.9(14.5)^{\mathrm{bA}}$ & $67.6(11.8)^{\mathrm{cA}}$ & $29.6(13.8)^{d B}$ \\
\hline
\end{tabular}

Means (S.D); $n=10$.

Same small letter within columns indicates no significant difference for individual materials and light curing times.

Same capital letter within rows indicates no significant difference for individual materials and depths.

curing, there was no significant interaction between the resin composite materials and light-curing time $(p=0.48)$, while, for VS measured after $24 \mathrm{~h}$ there was a significant interaction between the resin composite materials and light-curing time $(p=0.045)$.

When the light-curing time was $20 \mathrm{~s}$, VS measured immediately after light-curing were in the order of BBF, $\mathrm{EFQ}, \mathrm{EBF}$, and FBF. For all the resin composites, the VS measured immediately after light-curing decreased with a reduction in the light-curing time, in which $5 \mathrm{~s}$ light-curing significantly decreased VS compared with 20 s light-curing $(p<0.05)$. Additionally, for FBF, BBF 
and EFQ, 10 s light-curing also significantly decreased VS compared with $20 \mathrm{~s}$ light-curing $(p<0.05)$, while for $\mathrm{EBF}$, there was no significant difference in VS between 10 and $20 \mathrm{~s}$ light-curing times $(p>0.05)$. On the other hand, the $24 \mathrm{~h}$ period significantly increased the VS of all the resin composites for all the light-curing times $(p<0.05)$, in which VS measured after $24 \mathrm{~h}$ were in the order, BBF, EBF, FBF and EFQ. For bulk-fill resin composites (EBF, FBF, BBF), there was no significant difference in VS measured after $24 \mathrm{~h}$ between all the light-curing groups $(p>0.05)$, while for the conventional resin (EFQ), $5 \mathrm{~s}$ light-curing resulted in significantly higher VS than the 10 and $20 \mathrm{~s}$ light-curing durations $(p<0.05)$.

\section{Ultimate microtensile strength test}

The means and standard deviations of the regional UTS for each resin composite at each depth are shown in Table 3. Three-way ANOVA revealed that the UTS were significantly different according to the resin composite materials, light-curing time and depth $(p<0.0001$, respectively). There were no significant interactions in the UTS data among the resin composite materials, light-curing time and depth $(p=0.40)$, and there was a significant interaction between the resin composite materials and light-curing time $(p<0.0001)$, between the resin composite materials and depth $(p<0.0001)$, while there was no significant interaction between light-curing time and depth $(p=0.053)$.

For EBF, FBF, and EFQ, 5 s light-curing resulted in significantly lower UTS than 10 and 20 s light-curing at each depth $(p<0.05)$, while for BBF, the UTS of the superficial layer (1-2 mm) was not significantly different between all the light-curing times $(p>0.05)$. The curing depths of the bulk-fill resin composites (EBF, FBF, $\mathrm{BBF}$ ) were deeper than that of the conventional resin composite (EFQ). The curing depth of EFQ decreased with the reduction in light-curing time. However, for the bulk-fill resin composites, the effect of light-curing time on their curing depth varied among the materials. For FBF, there was no significant difference in UTS between $1-5 \mathrm{~mm}$ depths at each light-curing time $(p>0.05)$. For BBF, UTS with $20 \mathrm{~s}$ light-curing time did not differ significantly between $1-5 \mathrm{~mm}$ depths $(p>0.05)$, while the curing depth decreased with a reduction of light-curing time. For EBF, there was no significant difference in UTS between 1-4 $\mathrm{mm}$ depths at each light-curing time $(p>0.05)$, while UTS at $5 \mathrm{~mm}$ depth decreased significantly.

\section{DISCUSSION}

SS-OCT has been developed based on the concept of lowcoherence interferometry, which permits real-time noninvasive visualizing of internal biological and biomaterial structures. The light beam with infrared light waves used in SS-OCT is projected over a scattering sample, and backscattered light is transformed into a signal intensity that reveals depth-resolved information about the scattering and reflection of the light in the sample.
The signal is converted into computed software and can be reconstructed as a cross-sectional image of the sample with high-resolution, and the surface profile of the sample is clearly visualized as a bright line on the SSOCT image when the sample has a different refractive index from air. Recently, SS-OCT has been used for the detection of caries, tooth fractures, and secondary caries at the restoration-tooth interface in vivo and in vitro ${ }^{6,28)}$. Additionally, some studies have demonstrated that SSOCT can be used for the quantitative measurement of gaps between resin composite and cavity walls ${ }^{32)}$ and observation of real-time gap progression ${ }^{26)}$. A recent study using SS-OCT observation, reported that internal gap formations in resin composite restorations were correlated with the shrinkage parameters of resin composites $^{3)}$.

Generally, the polymerization shrinkage of resin composite develops with an increase in the degree of conversion thereby improving its mechanical properties $^{33,34)}$. In this study, the VS of the resin composites was calculated by measuring the distances in the vertical direction between the surface of the resin composite before and after light-curing on the SS-OCT image. In the present study, the VS of resin composites measured immediately after light-curing was around $0.5-2 \%$, which was in agreement with previous studies $^{35)}$. Additionally, for all the composites, VS measured immediately after light-curing decreased with a reduction in the light-curing time, and in particular, the $5 \mathrm{~s}$ light-curing group had significantly lower VS than the $20 \mathrm{~s}$ light-curing group. The reduction of the VS values would indicate a lower degree of conversion in the resin composites by light-irradiation. On the other hand, after a $24 \mathrm{~h}$ period, the VS of all the resin composites significantly increased, resulting in similar VS values between all the light-curing groups. Some studies using Raman micro spectroscopy have demonstrated that the degree of conversion of resin composites exhibited a significant increase after $24 \mathrm{~h}$ compared to those immediately after light-curing ${ }^{14,24)}$. It is well known that after light-curing, the degree of conversion of resin composite increases and the post-cure polymerization mostly occurs during the first $24 \mathrm{~h}$ after light-curing ${ }^{36)}$. Post-cure polymerization occurs because some portions of the radicals generated during light-irradiation are trapped within the heterogeneous network and can persist for extended periods ${ }^{37}$. With the progress of the time, trapped radicals can encounter pendant groups, resulting in additional conversion. Additionally, in composite samples with initially lower degrees of conversion, a higher amount of un-reacted radicals allows for the increased mobility to make contact with other reactive species in the polymer network, leading to further promotion of post-cure polymerization, whereas in highly polymerized samples, reactive sites are immobilized in the polymer network ${ }^{38-40)}$. The reason for the remarkable increase in VS in the $5 \mathrm{~s}$ light-curing group may be due to the fact that post-cure polymerization was more pronounced in resin composites with an initial lower degree of conversion. 
In this study, regional UTS of resin composite at each depth $(1-5 \mathrm{~mm})$ were measured using the microtensile test for evaluation of the mechanical properties after a $24 \mathrm{~h}$ period. Five seconds lightcuring gave significantly lower UTS in all the resin composites than 10 and 20 s light-curing, except for BBF in the superficial layer (1-2 $\mathrm{mm}$ depths). These results would indicate that, when light-curing is performed for $5 \mathrm{~s}$, post-cure polymerization might not lead to an improvement in the mechanical properties of resin composites. Light-curing for a sufficient time would seem to be important for obtaining the higher mechanical properties of resin composites even if postcure polymerization could be further generated with short duration light-curing.

Additionally, measurement of regional UTS at each depth is a useful method for evaluating the curing depth of resin composites, whereby their values are strongly influenced by the polymerization behavior of resin matrix compared with the measurement values of the microhardness test ${ }^{30)}$. In this study, the curing depth of bulk-fill resin composites (EBF, FBF, BBF) was deeper than that of the conventional resin composite (EFQ). The curing depth of EFQ decreased with a reduction in the light-curing time. However, for the bulk-fill resin composites used in this study, the effect of light-curing time on their curing depths varied. The effects of lightcuring on resin composite are dependent upon several factors; such as the light translucency of resin composite, the monomer composition and type, concentration of initiator, inhibitor and accelerator ${ }^{41)}$. In general, in order to increase the curing depth, bulk-fill resin composites display a higher translucency than conventional resin composites ${ }^{42}$. Higher translucency can be achieved by a reduction in filler content ${ }^{43)}$. FBF produced deeper curing depth than the other bulk-fill resin composites, except for $\mathrm{BBF}$ in the $20 \mathrm{~s}$ light-curing group. For FBF, in each light-curing group, there were no significant differences in UTS between 1-5 $\mathrm{mm}$ depths; therefore, the curing depth was not affected by the light-curing time. However, in the $5 \mathrm{~s}$ light-curing group, the superficial layers (1-2 $\mathrm{mm}$ depths) exhibited significantly lower UTS than those in the 10 and $20 \mathrm{~s}$ light-curing groups. These results might be strongly influenced by the higher translucency of FBF because FBF has a slightly lower filler fraction compared to the other resin composites ${ }^{12)}$. On the other hand, for BBF, the UTS with $20 \mathrm{~s}$ light-curing did not significantly differ between 1-5 $\mathrm{mm}$ depths, whereas the curing depth decreased with a reduction in the lightcuring time. However, the UTS of the superficial layers (1-2 mm depths) were not affected by light-curing time, which was not the case for FBF. These results would indicate that in the superficial layers (1-2 $\mathrm{mm}$ depths), BBF could sufficiently polymerize even when the lightcuring time was short. These differences between FBF and $\mathrm{BBF}$ might be due to differences in translucency and in concentration of photo-initiator/catalyst.

For EBF, at each light-curing time, there were no significant differences in UTS between 1-4 mm depths, while UTS decreased significantly at $5 \mathrm{~mm}$ depth.
These results indicate that $\mathrm{EBF}$ had a lower curing depth than FBF and BBF. However, the curing depth was not affected by light-curing time. Additionally, for EBF, VS measured immediately after light-curing was not significant different between the 10 and $20 \mathrm{~s}$ lightcuring times although for other resin composites, there was a significant difference in VS between the 10 and $20 \mathrm{~s}$ light-curing groups. These results indicate that EBF could be sufficiently polymerized with $10 \mathrm{~s}$ light-curing at 1-4 mm depths. EBF uses radical-amplified photopolymerization initiator (RAP) technology, in which energy from the initial stage of CQ excitation by light is transferred to the radical amplifier ${ }^{44)}$. The radical amplifier is subsequently excited, and then allowed to decompose to produce radical-amplifier-derived radicals. These radicals act as the polymerization initiator and react with monomers to generate polymers, producing the curing effect, which can lead to lower concentration of $\mathrm{CQ}$ and shorter light-curing time. This may be the reason why there was no significant difference in VS between the 10 and $20 \mathrm{~s}$ light-curing time. On the other hand, although EFQ also uses RAP technology, $10 \mathrm{~s}$ light-curing resulted in lower VS than $20 \mathrm{~s}$ lightcuring. Presumably, there might be difference in the concentration of CQ between EFQ and EBF.

The light transmission characteristics as well as the mechanical properties of resin composites are influenced by filler load, type, size and shape ${ }^{42)}$. Generally, higher filler load can decrease the polymerization shrinkage of resin composite ${ }^{45)}$. EBF and EFQ contain nano spherical silica-zirconia fillers. On the other hand, FBF contains nanocluster fillers and $\mathrm{BBF}$ contains surface prereacted glass-ionomer (S-PRG) filler. These fillers would have different optical properties, leading to various light scattering behaviors within the resin composites. Therefore, they might affect the curing depth and polymerization shrinkage of resin composites in addition to the effect of light-curing time. Further research is necessary to determine the optical effect of fillers on polymerization behavior of resin composites.

\section{CONCLUSIONS}

Within the limitations of this study, it was concluded that the VS of resin composites measured immediately after light-curing decreased with a reduction in the light-curing time (20, 10 and $5 \mathrm{~s})$. On the other hand, for all the resin composites, the VS values significantly increased after $24 \mathrm{~h}$ due to the post-cure polymerization, resulting in similar VS values at all the light-curing times. A short light-curing time of $5 \mathrm{~s}$ decreased the regional UTS of resin composites after a $24 \mathrm{~h}$ period compared with the 10 and 20 s light-curing protocols; therefore, even with post-cure polymerization, a short light-curing time would not lead to an improvement in the mechanical properties of resin composites. For the tested bulk-fill resin composites, the influence of lightcuring time on the curing depth was dependent upon the material, whereas the curing depth of the conventional resin composite was affected by light-curing time. 


\section{REFERENCES}

1) Yoon TH, Lee YK, Lim BS, Kim CW. Degree of polymerization of resin composites by different light sources. J Oral Rehabil 2002; 29: 1165-1173.

2) Calheiros FC, Braga RR, Kawano Y, Ballester RY. Relationship between contraction stress and degree of conversion in restorative composites. Dent Mater 2004; 20: 939-946.

3) Han SH, Sadr A, Tagami J, Park SH. Internal adaptation of resin composites at two configurations: Influence of polymerization shrinkage and stress. Dent Mater 2016; 32: 1085-1094.

4) Farahat F, Daneshkazemi AR, Hajiahmadi Z. The effect of bulk depth and irradiation time on the surface hardness and degree of cure of bulk-fill composites. J Dent Biomater 2016; 3: 284-291.

5) Ferracane JL. Resin composite: state of the art. Dent Mater 2011; 27: 29-38.

6) Turkistani A, Nakashima S, Shimada Y, Tagami J, Sadr A. Microgaps and demineralization progress around composite restorations. J Dent Res 2015; 94: 1070-1077.

7) Sousa-Lima RX, Silva L, Chaves L, Geraldeli S, Alonso R, Borges B. Extensive assessment of the physical, mechanical, and adhesion behavior of a low-viscosity bulk fill composite and a traditional resin composite in tooth cavities. Oper Dent 2017; 42: E159-E166.

8) Jung JH, Park SH. Comparison of polymerization shrinkage, physical properties, and marginal adaptation of flowable and restorative bulk fill resin-based composites. Oper Dent 2017; 42: 375-386

9) Politi I, McHugh LEJ, Al-Fodeh RS, Fleming GJP. Modification of the restoration protocol for resin-based composite (RBC) restoratives (conventional and bulk fill) on cuspal movement and microleakage score in molar teeth. Dent Mater 2018; 34: 1271-1277.

10) Prager M, Pierce M, Atria PJ, Sampaio C, Caceres E, Wolff $\mathrm{M}$, et al. Assessment of cuspal deflection and volumetric shrinkage of different bulk fill composites using non-contact phase microscopy and micro-computed tomography. Dent Mater J 2018; 37: 393-399.

11) Fronza BM, Rueggeberg FA, Braga RR, Mogilevych B, Soares LE, Martin AA, et al. Monomer conversion, microhardness, internal marginal adaptation, and shrinkage stress of bulkfill resin composites. Dent Mater 2015; 31: 1542-1551.

12) Garoushi S, Vallittu P, Shinya A, Lassila L. Influence of increment thickness on light transmission, degree of conversion and micro hardness of bulk fill composites. Odontology 2016; 104: 291-297.

13) Zorzin J, Maier E, Harre S, Fey T, Belli R, Lohbauer U, et al. Bulk-fill resin composites: polymerization properties and extended light curing. Dent Mater 2015; 31: 293-301.

14) Par M, Gamulin O, Marovic D, Klaric E, Tarle Z. Effect of temperature on post-cure polymerization of bulk-fill composites. J Dent 2014; 42: 1255-1260.

15) Benetti AR, Havndrup-Pedersen C, Honore D, Pedersen MK, Pallesen U. Bulk-fill resin composites: polymerization contraction, depth of cure, and gap formation. Oper Dent 2015; 40: 190-200.

16) Jang JH, Park SH, Hwang IN. Polymerization shrinkage and depth of cure of bulk-fill resin composites and highly filled flowable resin. Oper Dent 2015; 40: 172-180.

17) Tsujimoto A, Barkmeier WW, Takamizawa T, Latta MA, Miyazaki M. Mechanical properties, volumetric shrinkage and depth of cure of short fiber-reinforced resin composite. Dent Mater J 2016; 35: 418-424.

18) Tsujimoto A, Barkmeier WW, Takamizawa T, Latta MA, Miyazaki M. Depth of cure, flexural properties and volumetric shrinkage of low and high viscosity bulk-fill giomers and resin composites. Dent Mater J 2017; 36: 205-213.

19) Cook WD, Forrest M, Goodwin AA. A simple method for the measurement of polymerization shrinkage in dental composites. Dent Mater 1999; 15: 447-449.

20) de Gee AF, Feilzer AJ, Davidson CL. True linear polymerization shrinkage of unfilled resins and composites determined with a linometer. Dent Mater 1993; 9: 11-14.

21) Venhoven BA, de Gee AJ, Davidson CL. Polymerization contraction and conversion of light-curing BisGMA-based methacrylate resins. Biomaterials 1993; 14: 871-875.

22) Sakaguchi RL, Wiltbank BD, Shah NC. Critical configuration analysis of four methods for measuring polymerization shrinkage strain of composites. Dent Mater 2004; 20: 388396.

23) Sharp LJ, Choi IB, Lee TE, Sy A, Suh BI. Volumetric shrinkage of composites using video-imaging. J Dent 2003; 31: 97-103.

24) Par M, Gamulin O, Marovic D, Klaric E, Tarle Z. Raman spectroscopic assessment of degree of conversion of bulk-fill resin composites-changes at 24 hours post cure. Oper Dent 2015; 40: E92-101.

25) Atria PJ, Sampaio CS, Caceres E, Fernandez J, Reis AF, Giannini M, et al. Micro-computed tomography evaluation of volumetric polymerization shrinkage and degree of conversion of composites cured by various light power outputs. Dent Mater J 2018; 37: 33-39.

26) Hayashi J, Shimada Y, Tagami J, Sumi Y, Sadr A. Realtime imaging of gap progress during and after composite polymerization. J Dent Res 2017; 96: 992-998.

27) Makishi P, Shimada Y, Sadr A, Tagami J, Sumi Y. Nondestructive 3D imaging of composite restorations using optical coherence tomography: marginal adaptation of selfetch adhesives. J Dent 2011; 39: 316-325.

28) Shimada Y, Sadr A, Sumi Y, Tagami J. Application of optical coherence tomography (OCT) for diagnosis of caries, cracks, and defects of restorations. Curr Oral Health Rep 2015; 2: 7380 .

29) Rueggeberg FA, Ergle JW, Mettenburg DJ. Polymerization depths of contemporary light-curing units using microhardness. J Esthet Dent 2000; 12: 340-349.

30) Nayif MM, Nakajima M, Aksornmuang J, Ikeda M, Tagami J. Effect of adhesion to cavity walls on the mechanical properties of resin composites. Dent Mater 2008; 24: 83-89.

31) Shibasaki S, Takamizawa T, Nojiri K, Imai A, Tsujimoto $\mathrm{A}$, Endo $\mathrm{H}$, et al. Polymerization behavior and mechanical properties of high-viscosity bulk fill and low shrinkage resin composites. Oper Dent 2017; 42: E177-187.

32) Bakhsh TA, Sadr A, Shimada Y, Tagami J, Sumi Y. Noninvasive quantification of resin-dentin interfacial gaps using optical coherence tomography: validation against confocal microscopy. Dent Mater 2011; 27: 915-925.

33) Sakaguchi RL, Berge HX. Reduced light energy density decreases post-gel contraction while maintaining degree of conversion in composites. J Dent 1998; 26: 695-700.

34) Feilzer AJ, Dooren LH, de Gee AJ, Davidson CL. Influence of light intensity on polymerization shrinkage and integrity of restoration-cavity interface. Eur J Oral Sci 1995; 103: 322326.

35) Naoum SJ, Ellakwa A, Morgan L, White K, Martin FE, Lee IB. Polymerization profile analysis of resin composite dental restorative materials in real time. J Dent 2012; 40: 64-70.

36) Pilo R, Cardash HS. Post-irradiation polymerization of different anterior and posterior visible light-activated resin composites. Dent Mater 1992; 8: 299-304.

37) Burtscher P. Stability of radicals in cured composite materials. Dent Mater 1993; 9: 218-221.

38) Trujillo M, Newman SM, Stansbury JW. Use of near-IR to monitor the influence of external heating on dental composite photopolymerization. Dent Mater 2004; 20: 766-777. 
39) Halvorson RH, Erickson RL, Davidson CL. Energy dependent polymerization of resin-based composite. Dent Mater 2002; 18: 463-469.

40) Lovell LG, Newman SM, Bowman CN. The effects of light intensity, temperature, and comonomer composition on the polymerization behavior of dimethacrylate dental resins. J Dent Res 1999; 78: 1469-1476.

41) Nomoto R, Hirasawa T. Residual monomer and pendant methacryloyl group in light-cured composite resins. Dent Mater J 1992; 11: 177-188.

42) Bucuta S, Ilie N. Light transmittance and micro-mechanical properties of bulk fill vs. conventional resin based composites. Clin Oral Investig 2014; 18: 1991-2000.

43) Lee YK. Influence of filler on the difference between the transmitted and reflected colors of experimental resin composites. Dent Mater 2008; 24: 1243-1247.

44) Ilie N, Kreppel I, Durner J. Effect of radical amplified photopolymerization (RAP) in resin-based composites. Clin Oral Investig 2014; 18: 1081-1088.

45) Kleverlaan CJ, Feilzer AJ. Polymerization shrinkage and contraction stress of dental resin composites. Dent Mater 2005; 21: 1150-1157. 